\title{
Attitudes and beliefs towards physical activity participation in individuals with below-knee amputation
}

Prasath Jayakaran $P h D$

Lecturer, School of Physiotherapy, University of Otago, Dunedin, New Zealand

Meredith Perry PhD

Senior Lecturer, School of Physiotherapy, University of Otago, Wellington, New Zealand

Marko Kondov* BPhty

School of Physiotherapy, University of Otago, Dunedin, New Zealand

Tessa McPherson* BPhty

School of Physiotherapy, University of Otago, Dunedin, New Zealand

Leigh Sutherland* BPhty

School of Physiotherapy, University of Otago, Dunedin, New Zealand

Adela Wypych* BPhty

School of Physiotherapy, University of Otago, Dunedin, New Zealand

*Undergraduate students at the time of the study

\section{ABSTRACT}

An amputation causes irreversible life-changing impairments as well as physical and mental changes. Individuals with an amputation face major challenges in terms of physical function, affecting activities of daily living and participation in regular physical activity. Exploring the views of individuals with a below-knee amputation towards physical activity is necessary for broadening understanding of perceptions, including motivations and barriers. Participants were recruited from respondents who had completed a survey that explored physical activity in people with a below-knee amputation. Semi-structured interviews conducted via telephone were audiorecorded and analysed using the general inductive approach. Seven individuals with a below-knee amputation were included in this study. Two broad categories were identified: personal factors and support factors. Within these categories four subcategories arose: attitudes, health, social support, environment and services. We found that both internal and external factors influence the perceptions of individuals with an amputation towards physical activity. These factors also largely interacted with each other. In addition, current and previous activity levels influenced views towards physical activity. Behaviour change interventions, such as motivational interviewing, may improve physical activity participation of individuals with a below-knee amputation.

\section{Jayakaran, P., Perry, M., Kondov, M., McPherson, T., Sutherland, L. \& Wypych, A. (2019). Attitudes and beliefs towards physical activity participation in individuals with below-knee amputation. New Zealand Journal of Physiotherapy 47(2), 118-128. https://doi.org/10.15619/NZJP/47.2.06}

Key Words: Attitude, Beliefs, Below-knee Amputation, Exercise, Qualitative Research

\section{INTRODUCTION}

Physical activity positively enhances the health and well-being of all individuals (Bize, Johnson, \& Plotnikoff, 2007; Haskell et al., 2007). Physical activity is defined as "any bodily movement that results in an increase in energy expenditure" (Caspersen, Powell, \& Christenson, 1985, p. 126), and thus includes incidental and intentional activities, such as work, sports and home-related activities that result in energy expenditure. It is associated with a wide range of health benefits, such as prevention of chronic diseases, and improvement in cardiovascular and psychological functioning (Bragaru et al., 2013). Regular participation in physical activity has also been shown to improve overall wellbeing and quality of life in the general population (Bize et al., 2007), particularly when minimum recommended intensity and frequency guidelines are met (World Health Organisation, 2010). However, due to a number of personal, social and environmental factors, $60 \%$ of the general population in New Zealand and comparable Western countries are physically inactive (Giles-Corti \& Donovan, 2002; Seefeldt, Malina, \& Clark, 2002), resulting in an estimated five million deaths per year (Sallis et al., 2016).

Individuals with a physical disability may have additional physical, social and psychological challenges that inhibit regular intentional and incidental physical activity participation (Rimmer \& Marques, 2012; Rimmer, Riley, Wang, Rauworth, \& Jurkowski, 2004). Lower limb amputation causes a permanent physical disability, which can negatively impact psychosocial functioning and mental health (Bragaru, Dekker, Geertzen, \& Dijkstra, 2011; Da Silva, Rizzo, Gutierres Filho, Ramos \& Deans, 2011; Vissers et al., 2008). In addition, physical disability factors, such as postural and gait asymmetries (Gaunaurd, Gailey, Hafner, GomezMarin, \& Kirk-Sanchez, 2011), and the increased metabolic 
cost of walking (Nolan \& Lees, 2000; Waters \& Mulroy, 1999), may present as significant barriers to engagement in physical activity. However, the benefits of physical activity in this specific population include a range of physical and psychological factors, such as increased cardiopulmonary function, reduced stress and depression, and improved body image (Bragaru et al., 2011; Tatar, 2010; Wetterhahn, Hanson, \& Levy, 2002). Despite these benefits, the number of adults with amputations who engage in regular physical activity is less than half of age-matched adults with intact lower limbs (Kars, Hofman, Geertzen, Pepping, \& Dekker, 2009).

In New Zealand, one in 1,000 people have an amputation, and reportedly, the most common causes of amputation are dysvascular (52\%) and traumatic (31\%) (New Zealand Artificial Limb Service, 2018). Recent findings from a national crosssectional survey of adults with a below-knee amputation in New Zealand suggest that individuals with an amputation perceived physical activity participation as having positive benefits (Jayakaran, Perry, \& Hale, 2018), as measured by the Exercise Benefits and Barriers Scale (Sechrist, Walker, \& Pender, 1987). However, this perception did not positively correlate with reported physical activity levels. There is currently no New Zealand specific research on why individuals with an amputation may engage less in physical activity, and there is a need to explore the perspectives of individuals with an amputation in New Zealand, which may be unique. Therefore, the aim of this study was to explore the attitudes of individuals with a belowknee amputation towards physical activity.

\section{METHODS}

\section{Study design}

This study used a qualitative design, which included individual, semi-structured interviews of the participants. Ethical approval was obtained from the University of Otago Human (Health) Ethics Committee (ref: H14/121), and all participants provided written informed consent prior to participation.

\section{Participants}

Participants were recruited from a cohort of individuals who had earlier completed a survey (conducted between May 2015 and December 2015) and indicated that they would be interested in being contacted for an interview (Jayakaran et al., 2018). Individuals aged 40 years and over with a belowknee amputation due to a trauma or a dysvascular condition were included in the study. Individuals who had received an amputation more than a year ago and were using a lower limb prosthesis to assist with the performance of daily functional activities were also included. Participants were excluded if they had a history of trauma, fracture or surgeries to the lower limb within the past year.

\section{Procedures}

Participants were initially contacted by telephone and asked whether they were interested in participating in the study. Those that agreed were forwarded the information sheet and written consent form via email or post with a return envelope. Once written informed consent had been obtained, dates and times for the individual, semi-structured telephone interviews were scheduled. Participants were not compensated for their involvement in the study.
A semi-structured interview guide (Appendix 1) was developed by members of the research team. The guide consisted of eight main topic categories, with related sub-questions. The guide followed a similar structure to that used by Bragaru et al. (2013), with the interview starting with an informal conversation about the participant's age, occupation and amputation characteristics. Participants were then asked if they had questions and wished to continue further. Following this, participants were asked questions relating to their perception of their own health and activity. All questions were open-ended to encourage freeflowing conversation based around health; physical activity; and physical activity facilitators, barriers, and support. Where necessary, prompts were used to elicit a more detailed response. If participants strayed too far from the topic, the interviewer used the guide to start a new topic and to steer them back to the core of the discussion. To ensure that the interview questions/prompts followed a logical order, the interview guide was trialled once with an adult aged over 60 years who had initially been non-weight bearing and then partially weight bearing on the right leg for over 10 months. Following the trial interview, the guide was adapted and improved in order to best collect unanticipated meanings and attitudes of the individuals (Bragaru et al., 2013).

All interviews were conducted in English and were recorded with a mobile device. The duration of each interview ranged from 20 to 40 minutes. To ensure validity of results, one interviewer conducted all interviews (MK). Other team members were present during the interview to take notes of key concepts and, if needed, prompt interviewer on topics (Kallio, Pietilä, Johnson, \& Kangasniemi, 2016). All interviews were transcribed verbatim and recordings were destroyed after transcription. Participants were coded P1 to P7 and with either a " $T$ " for traumatic amputation or "D" for dysvascular amputation.

\section{Analysis}

The transcribed raw data were analysed following the general inductive approach (Thomas, 2006) and coded for key ideas relating to the research objective. This approach provides a systematic procedure for the analysis of qualitative data to discover valid and reliable findings, particularly when researchers are unfamiliar with any of the traditional approaches to qualitative analysis (Thomas, 2006). Independent parallel coding was undertaken to ensure trustworthiness of the coding (Figure 1). The transcripts were read thoroughly, four times each, and then coded for the key ideas that were identified in the text. A Microsoft Excel spreadsheet was used to record the key ideas with supporting quotes. These ideas were then further grouped to create major themes. Alterations were made to the spreadsheet as needed during team meetings/discussions. The major themes were identified from the combination of key ideas that had similar overall concepts. Finally, the themes were further grouped into broader categories according to overarching similarities relating to either personal factors or support factors. These themes were discussed within the team to ensure the relevance to key research objectives. Member checks were completed with research participants to ensure that the derivation of themes was representative of their beliefs towards physical activity. 


\section{CODING}

Interviews were read and coded individually by 4 members of the team.

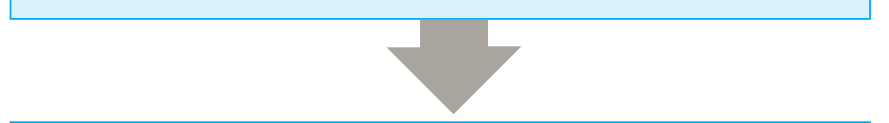

\section{COMBINING CATEGORIES}

Team members met in groups of 2 to discuss categories and merge where applicable.

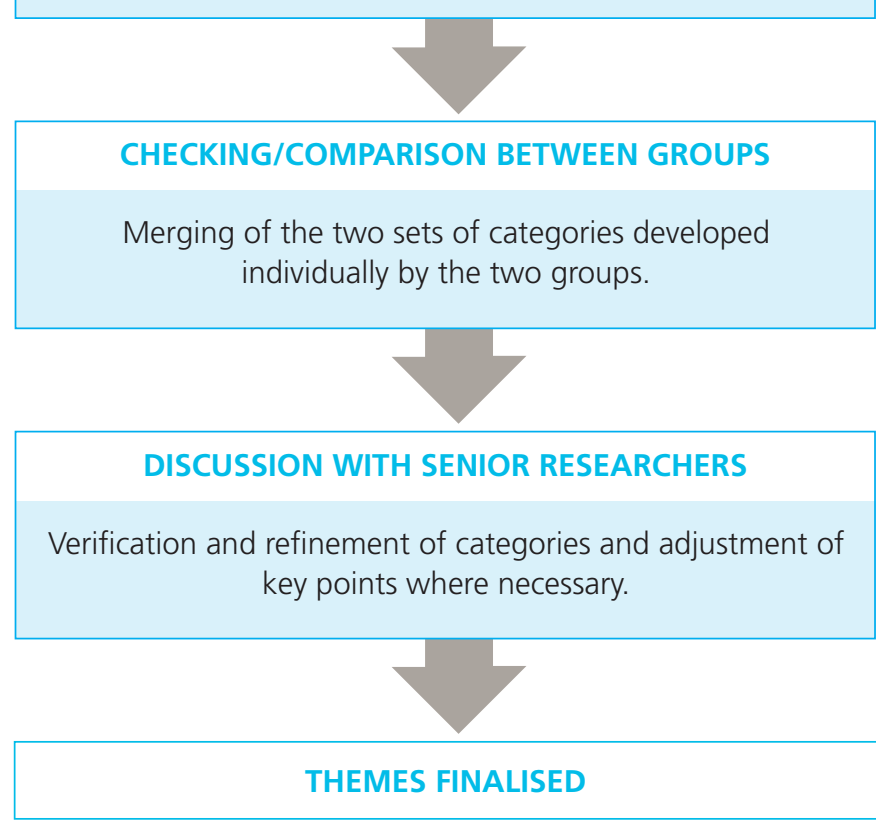

Figure 1: Flow diagram of data deduction and analysis process

Personal Factors:
- Attitude:
- Body image
- Independence
- Participation
- Past activity levels
- Enjoyable activities
- Health:
- Physical heatlh
- Amputation
- Fitness
- Medical health
- Mental health
- Quality of life
- Self efficacy

\section{Support: \\ - Social support: \\ - Family \\ - Friends \\ - Religious/cutural groups \\ - Community groups}

- Environmental and services:

- Nature/surfaces

- Carparks

- Housing

- Lawns and gardens

- Financial services

- Organised support services (home help and gardners)
Figure 2: Individual items that influenced participants' views of physical activity

\section{RESULTS}

A total of 25 individuals who met the inclusion criteria were approached, and seven of these participated in this study (dysvascular $n=2$, traumatic $n=5$ ). The mean age of participants was 65 (standard deviation 8) years (Table 1). A top-down approach was used when deducing the themes from the interviews. The important emerging ideas from the interviews were organised into four major themes: attitude, health, social support and environment/services. These themes were further identified into two categories: personal factors and external factors (Figure 2). The themes identified in this study gave a deeper understanding towards the positive and negative attitudes relating to physical activity participation. The supporting quotes for the major themes are detailed in Appendix 2.

\section{Table 1: Participants demographic information $(n=7)$}

\begin{tabular}{cccc}
\hline Participant & Sex & Age (years) & Cause of amputation \\
\hline P1 & Male & 62 & Traumatic \\
P2 & Male & 75 & Traumatic \\
P3 & Male & 58 & Traumatic \\
P4 & Male & 64 & Traumatic \\
P5 & Male & 58 & Traumatic \\
P6 & Male & 60 & Dysvascular \\
P7 & Male & 79 & Dysvascular \\
\hline
\end{tabular}

\section{Personal factors}

Attitude: Five of the seven participants felt that being physically active allowed them to be seen by others and themselves as the same person they were before losing their limb. They did not feel nor want to be seen differently, as P3T said: "... to prove to people that ... my leg doesn't disadvantage me ... I pushed myself to prove that I was the same bloke that I was beforehand." For these participants, physical activity participation meant that others may not see them as a person with a disability, as they were still free to do things independently for themselves.

For many participants, being active was ingrained in their personality, and it was a part of who they were. Maintaining an active lifestyle post-amputation enhanced their self-efficacy and positively reinforced being active throughout their life. Certain activities, such as fishing, gardening and, for one participant, regular work, enabled them to feel like the same person they were prior to their amputation. It helped them regain their self-identity and sense of self. In order to remain active, one participant discussed how their mindset allowed them to continue with their activities: "I don't um dwell on having lost a leg and I still do what I want to do." (P3T)

However, two participants had opposing views on remaining physically active due to personal barriers. These individuals felt they had lost their sense of self, had increased reliance on others and could not participate in physical activity. These participants also felt that even their daily tasks were extremely challenging. 
While they valued physical activity, they did not see themselves as capable of it. For example: "It's torture, I can't do it. I can't do any physical activity at all ... I can hardly walk, I fall over a lot" (P7D).

Health: This theme includes both physical and mental health. For five of the participants, physical activity was seen as a positive health behaviour, with a number of positive health benefits. These participants identified that a motivator for physical activity was physical benefits and believed that these benefits included weight loss; lowered resting heart rate, blood cholesterol and blood pressure; and improved mobility and fitness. For example, one participant said: "Yeah that's the full exercise I do to keep my fitness up" (P6D). Two participants also discussed improvement in their quality of life. For example: "If I want a better quality of life, nobody is going to give that to me, I have to do that myself" (P6D). Physical activity participation was perceived by four participants to improve mental health by enhancing a positive attitude following an amputation.

Despite these views, three participants stated that their current or ongoing poor health limited their ability to participate in physical activity. All participants in this study identified that the biggest barrier to physical activity participation was the issues following the amputation, such as phantom pain, stump pain associated with the prosthesis, loss of balance and other comorbidities. For example, one participant said: "The stump gets sore, that's what would stop me" (P4T).

\section{External factors}

Social support: All seven participants found that adequate social support networks encouraged them to participate in physical activity. Social support enhanced participants' ability to cope with potential barriers preventing physical activity and improved their participation in daily activities. Social support networks included family, friends, community groups and employers which enabled the continuation of enjoyable activities and everyday tasks. For example: "I can still get out there and fish because I got friends that take me out fishing" (P6D). Family members often arose as a key support network: "My wife will take my arm, just for balance, just in case someone bumps into $m e^{\prime \prime}$ (P3T). This illustrates the importance for individuals with an amputation to feel supported.

Two participants felt that inadequate social support networks led to a reduction in their ability to cope with physical activity in the community or home. One participant, who was a keen fisherman and owned a boat but could no longer balance to safely steer it. They discussed how lack of social support affected his participation in this hobby, stating: "I sort of don't have anybody with a boat to go out with..." (P4T). While another suggested that additional support was necessary for resuming their previous leisure activities: "Nobody caters for the disabled ... once you get out of hospital you never see anybody ... you're sort of left to your own devices" (P2T).

Environment and services: A number of individuals found a way to adapt their environment to suit their needs. One participant acknowledged their own limitations, but also actively problem solved so they could complete daily activities: "I have to use a shower stool all the time. I find it a bit safer, you don't slip over" (P2T). Other participants acknowledged that certain services enabled their participation in enjoyable activities: "The library down here has been adapted so that there is no limitation. I can just wheel in and the door opens and I go and read my reading" (P6D). Services such as transportation, financial aid, rehabilitation and personal services enabled some participants to remain active in their environments. For example: "I use a disability sticker on the car so I park as close as I can... when I go shopping" (P4T). This suggests that this participant was then able to walk a more manageable distance, thereby increasing their physical activity.

A few participants found that services provided to them were inadequate and proved to be a limiting factor towards achieving physical activity. One participant stated that some routes/paths prevented them from being mobile in the community: "I find soft sand and gravel a bit of a bugger to walk in and up and down hills" (P2T). However, other participants persevered within the limitations of the environment, even if it meant they had to be extra vigilant to prevent a fall: "Definitely got to be careful of footpaths, especially if it's raining, it's slippery" (P4T).

Lack of services, such as public transport, indirectly limited participants' ability to engage in activity: "Lack of transport; I just can't really get around" (P5T). Finances also had an indirect effect on the ability of participants to remain physically active: "I haven't got a whole lot of finances, by the time you pay your bills and everything, you haven't really got a lot left to do anything" (P5T).

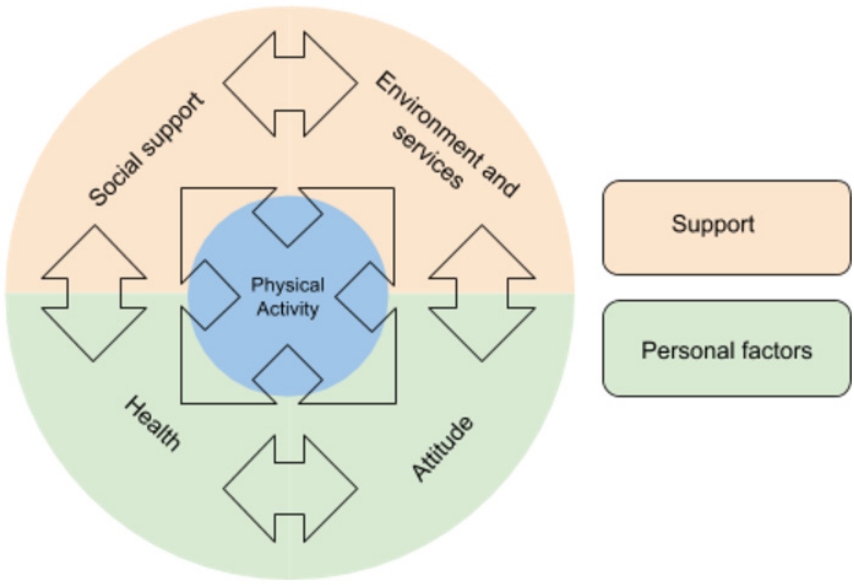

Figure 3: Illustration of major theme interactions

\section{Theme interaction}

An overview of theme interactions is illustrated in Figure 3. It shows that the main themes cannot be considered separately due to their close relationship with one another - they all had an impact on the views of physical activity. Many interactions between the four main themes were observed during our analysis. For example, one participant mentioned his passion for gardening and that he liked to be out in the garden alone, but he was unable to dig up the garden, and so his family would help him with this. This shows the complex relationship between his beliefs, values and attitude in wanting to be independent in physical activity of personal meaning to him, while admitting the need for support from family due to his physical limitations: "I' $m$ passionate about gardening and I can still do those things... [though] I need somebody around me to dig the garden up and so forth" (P6D). 


\section{Member checks}

In order to ensure interpretations made from our analysis of the data were accurate, a summary of our key findings and figures were sent to all study participants. Of the two participants who replied, both agreed strongly with the findings. One participant highlighted the importance of fortnightly visits with his facilitator, motivating him to achieve physical activity goals that had been previously set, which emphasised the importance of having someone to share goals with. The other participant said: "There is no single thing that could be improved to benefit all amputees" (P3T). This participant also said his age at amputation was a key factor for him, an idea not previously mentioned in this study: "I had the advantage of still being a young man with the desire to achieve a normal life when I lost my leg" (P3T).

\section{DISCUSSION}

The purpose of this study was to better appreciate the perceptions towards physical activity of individuals with a lower limb amputation. We found common attitudes about physical activity were determined by both personal and external factors, such as individual beliefs and values, and the environment respectively. These factors have been understood to contribute both positively and negatively towards the views of individuals with an amputation on physical activity.

Further, we also identified an interaction between the four themes. Similar to the findings of the current study, Lui and Hui (2009) identified interactions between personal factors, disability and health, and the environment for individuals with physical disabilities. An individual's attitude towards physical activity could be influenced by their health, including their self-efficacy and locus of control beliefs; the support they have around them; and their environment (Castellani, lanni, Ricca, Mannucci, \& Rotella, 2003; Woodard \& Berry, 2001). This suggests that in order to alter views about physical activity it is necessary to understand how these other factors influence attitudes towards physical activity. Participants of the current study mentioned the need for support from others in order to participate in physical activities and described how their social support networks also helped them maintain their independence. This finding identifies a link between physical activity, social support and a general attitude towards physical activity participation.

It was apparent in our study that the participants who were active pre-amputation often remained active post-amputation (Bragaru et al., 2013). The participants who were active when interviewed had positive attitudes towards physical activity. Conversely, participants who viewed themselves as inactive believed physical activity to be impossible and, as a result, were unlikely to change their behaviours even though they acknowledged that physical activity might be of benefit to their long-term health. Physical activity can include a range of activities, and the current study adopted the broader definition of physical activity, which can range from low-intensity walking to high-intensity, vigorous activity. Previous research investigating chronic conditions identified individuals as the main facilitator or manager for their long-term care (Clark, Gong, \& Kaciroti, 2014). Reportedly, individuals with asthma were more likely to use corticosteroid inhalers if they saw these as beneficial within the self-management of their condition.
Similarly, able-bodied and physically disabled participants who valued the benefits of physical activity were more likely to use physical activity participation as a self-management strategy for health (Giles-Corti \& Donovan, 2002) and their condition (Allender, Cowburn, \& Foster, 2006), respectively.

Participants in the current study were solely responsible for the amount of physical activity they undertook to manage their physical and mental health. Some of the participants discussed the perceived health benefits that physical activity had afforded them as a reason for their continued participation. However, unlike previous findings (Allender et al., 2006; Giles-Corti \& Donovan, 2002), the participants who deemed themselves inactive were also aware of the benefits of physical activity. While they did not undervalue physical activity participation, they perceived it as impossible due to their condition or personal circumstances. Brawley, Rejeski, and King (2003) found that factors such as perceived poor health and pain relating to their comorbidities inhibited the ability of the individuals in their study to be active.

Self-efficacy is a determinant in participation of regular, intentional and structured physical activity in a clinical population (Castellani et al., 2003; Woodard \& Berry, 2001). Participants of the current study who perceived themselves as physically active appeared to have fewer barriers when engaging in physical activity. The decision to engage in regular physical activity participation was positively reinforced via improved quality of life and socialisation. Additionally, these participants perceived that decreased physical activity would result in negative consequences. Therefore, strategies to overcome this may benefit long-term improvement of physical activity in individuals with an amputation. Kirk, MacMillan, and Webster (2010) reported that individuals with type-2 diabetes mellitus and/or cardio-vascular diseases who have progressed to higher stages of behaviour change reported higher levels of physical activity and self-efficacy. Although individuals with an amputation may have different challenges, the relationship between the trans-theoretical model of change and physical activity participation may be true for the amputation population. Motivational interviewing could be a tool clinicians use as it is designed to find a constructive way to elicit behaviour change within the individual (Miller \& Rollnick, 2013). Both the transtheoretical model of change and motivational interviewing could be used as tools to facilitate behaviour change about physical activity and improve activity levels for individuals with an amputation.

As far as we are aware, this is the first qualitative study to explore the attitudes and beliefs towards physical activity in persons living in New Zealand with a below-knee amputation. This means that qualitative data and results derived from the study are more of a representation of individuals with a belowknee amputation in New Zealand. Our results may differ from findings in other countries due to alternate cultural beliefs (Brink, 2001). Our research is important as it can help to inform clinicians of the perceptions of individuals with a below-knee amputation towards physical activity, and offer potential strategies to effectively motivate patients to engage in physical activity (Öhman, 2005). 
Member checks were performed in order to improve trustworthiness and credibility of collected data (Öhman, 2005). Independent parallel coding was performed in order to account for different interpretations of data, and enhance consistency in the data analysis process (Thomas, 2006).

All participants interviewed in the study were males, and the views of females in physical activity participation is not known. While, this is a limitation of the findings, it should be noted that amputations are typically more prevalent in the male population (Sarvestani \& Azam, 2013).

The current study included participants with dysvascular and trauma amputations, which are the primary aetiologies of amputation in New Zealand. The beliefs and attitudes of individuals with a dysvascular amputation may be different from that of individuals with a traumatic amputation. The current study was not able to differentiate this due to a small sample size. Future research should build on the current findings and explore any differences between the aetiologies.

Other potential limitations include lack of interviewer experience. While the quality of the data can be dependent on the researcher's skill and experience (Öhman, 2005), we performed a trial interview and three interviews with an experienced qualitative researcher as a support person. The interview guide also helped minimise this limitation by promoting consistency with the interviews.

\section{CONCLUSION}

All relationships between themes, identified from our interviews, had both positive and negative aspects. Despite identifying multiple different themes, we found that there was significant interdependence between themes for participants. We found that those individuals who could still participate in physical activity had more positive views relating to physical activity and could more readily find solutions to barriers. Conversely, participants who found day-to-day living difficult were less likely to remain active, and identified more barriers (and fewer strategies) which prevented them from participating in physical activity. Another key finding was that participants who expressed a positive view on physical activity participation may be at a higher stage of behaviour change readiness compared to those who perceive more barriers in physical activity participation. Behaviour change interventions, such as motivational interviewing targeting self-efficacy of individuals or collaborative goal setting may improve the physical activity participation of individuals with a below-knee amputation.

\section{KEY POINTS}

1. Individuals who participated in physical activity had more positive views towards overcoming their barriers.

2. Individuals with a positive view on physical activity participation may be at a higher stage of behaviour change readiness compared to those who perceive more barriers in physical activity participation.

3. Behaviour change interventions, such as motivational interviewing targeting self-efficacy of individuals or a collaborative goal setting, may improve the physical activity participation of individuals with a below-knee amputation.

\section{DISCLOSURES}

There are no conflicts of interest which may be perceived to interfere with or bias this study.

\section{PERIMISSIONS}

This study was approved by the University of Otago Human Ethics (Health) Committee (ref: H14/121).

\section{ACKNOWLEDGEMENTS}

We acknowledge the participants for their time and for sharing their thoughts with us.

\section{ADDRESS FOR CORRESPONDENCE}

Dr Prasath Jayakaran, Lecturer, Centre for Health, Activity and Rehabilitation Research, School of Physiotherapy, University of Otago, Dunedin 9016, New Zealand. Tel: +64 34795428. Email: prasath.jayakaran@otago.ac.nz.

\section{REFERENCES}

Allender, S., Cowburn, G., \& Foster, C. (2006). Understanding participation in sport and physical activity among children and adults: A review of qualitative studies. Health Education Research, 21(6), 826-835. https://doi.org/10.1093/her/cyl063

Bize, R., Johnson, J. A., \& Plotnikoff, R. C. (2007). Physical activity level and health-related quality of life in the general adult population: A systematic review. Preventive Medicine, 45(6), 401-415. https://doi. org/10.1016/j.ypmed.2007.07.017

Bragaru, M., Dekker, R., Geertzen, J. H. B., \& Dijkstra, P. U. (2011). Amputees and sports: A systematic review. Sports Medicine, 41(9), 721-740. https://doi.org/10.2165/11590420-000000000-00000

Bragaru, M., van Wilgen, C. P., Geertzen, J. H. B., Ruijs, S. G. J. B., Dijkstra, P. U., \& Dekker, R. (2013). Barriers and facilitators of participation in sports: A qualitative study on Dutch individuals with lower limb amputation. PLOS ONE, 8(3), e59881. https://doi. org/10.1371/journal.pone.0059881

Brawley, L. R., Rejeski, W. J., \& King, A. C. (2003). Promoting physical activity for older adults: The challenges for changing behavior. American Journal of Preventive Medicine, 25(3 Suppl 2), 172-183. https://doi.org/10.1016/s0749-3797(03)00182-x

Brink, P. J. (2001). Representing the population in qualitative research. Western Journal of Nursing Research, 23(7), 661-663. https://doi. org/10.1177/01939450122045465

Caspersen, C. J., Powell, K. E., \& Christenson, G. M. (1985). Physical activity, exercise, and physical fitness: Definitions and distinctions for health-related research. Public Health Reports, 100(2), 126-131.

Castellani, W., Ianni, L., Ricca, V., Mannucci, E., \& Rotella, C. M. (2003). Adherence to structured physical exercise in overweight and obese subjects: A review of psychological models. Eating and Weight Disorders - Studies on Anorexia, Bulimia and Obesity, 8(1), 1-11. https://doi.org/10.1007/bf03324983

Clark, N. M., Gong, M., \& Kaciroti, N. (2014). A model of self-regulation for control of chronic disease. Health Education \& Behavior, 41(5), 499-508. https://doi.org/10.1177/109019810102800608

Da Silva, R., Rizzo, J. G., Gutierres Filho, P. J. B., Ramos, V., \& Deans, S. (2011). Physical activity and quality of life of amputees in southern Brazil. Prosthetics and Orthotics International, 35(4), 432-438. https://doi.org/10.1177/0309364611425093

Gaunaurd, I., Gailey, R., Hafner, B. J., Gomez-Marin, O., \& KirkSanchez, N. (2011). Postural asymmetries in transfemoral amputees. Prosthetics and Orthotics International, 35(2), 171-180. https://doi. org/10.1177/0309364611407676

Giles-Corti, B., \& Donovan, R. J. (2002). The relative influence of individual, social and physical environment determinants of physical activity. Social Science and Medicine, 54(12), 1793-1812. https://doi. org/10.1016/S0277-9536(01)00150-2 
Haskell, W. L., Lee, I. M., Pate, R. R., Powell, K. E., Blair, S. N., Franklin, B. A., . . Bauman, A. (2007). Physical activity and public health: Updated recommendation for adults from the American College of Sports Medicine and the American Heart Association. Circulation, 116(9), 1081-1093. https://doi.org/10.1161/ CIRCULATIONAHA.107.185649

Jayakaran, P., Perry, M., \& Hale, L. (2018). Comparison of self-reported physical activity levels and quality of life between individuals with dysvascular and non-dysvascular below-knee amputation: A crosssectional study. Disability and Health Journal, 12(2), 235-241. https:// doi.org/10.1016/j.dhjo.2018.10.005

Kallio, H., Pietilä, A. M., Johnson, M., \& Kangasniemi, M. (2016). Systematic methodological review: developing a framework for a qualitative semi-structured interview guide. Journal of Advanced Nursing, 72(12), 2954-2965. https://doi.org/10.1111/jan.13031

Kars, C., Hofman, M., Geertzen, J. H., Pepping, G. J., \& Dekker, R. (2009). Participation in sports by lower limb amputees in the Province of Drenthe, The Netherlands. Prosthetics and Orthotics International, 33(4), 356-367. https://doi.org/10.3109/03093640902984579

Kirk, A., MacMillan, F., \& Webster, N. (2010). Application of the transtheoretical model to physical activity in older adults with type 2 diabetes and/or cardiovascular disease. Psychology of Sport and Exercise, 11(4), 320-324. https://doi.org/10.1016/j. psychsport.2010.03.001

Lui, K. C., \& Hui, S. S. C. (2009). Participation in and adherence to physical activity in people with physical disability. Hong Kong Physiotherapy Journal, 27(1), 30-38. https://doi.org/10.1016/S10137025(10)70006-3

Miller, W. R., \& Rollnick, S. (2013). Motivational interviewing: helping people change (3rd ed.). New York: Guilford Press.

New Zealand Artificial Limb Service. (2018). Retrieved from https:// www.nzals.co.nz/assets/Uploads/Annual-Report/NZALS-AnnualReport-2018.pdf

Nolan, L., \& Lees, A. (2000). The functional demands on the intact limb during walking for active trans-femoral and trans-tibial amputees. Prosthetics and Orthotics International, 24(2), 117-125. https://doi. org/10.1080/03093640008726534

Öhman, A. (2005). Qualitative methodology for rehabilitation research. Journal of Rehabilitation Medicine, 37(5), 273-280. https://doi. org/10.1080/16501970510040056

Rimmer, J. H., \& Marques, A. C. (2012). Physical activity for people with disabilities. Lancet, 380(9838), 193-195. https://doi.org/10.1016/ S0140-6736(12)61028-9
Rimmer, J. H., Riley, B., Wang, E., Rauworth, A., \& Jurkowski, J. (2004). Physical activity participation among persons with disabilities: Barriers and facilitators. American Journal of Preventive Medicine, 26(5), 419-425. https://doi.org/10.1016/j.amepre.2004.02.002

Sallis, J. F., Cerin, E., Conway, T. L., Adams, M. A., Frank, L. D., Pratt, M., ... Owen, N. (2016). Physical activity in relation to urban environments in 14 cities worldwide: A cross-sectional study. Lancet, 387(10034), 2207-2217. https://doi.org/10.1016/s01406736(15)01284-2

Sarvestani, A. S., \& Azam, A. T. (2013). Amputation: A ten-year survey. Trauma Monthly, 18(3), 126-129. https://doi.org/10.5812/ traumamon.11693

Sechrist, K. R., Walker, S. N., \& Pender, N. J. (1987). Development and psychometric evaluation of the exercise benefits/barriers scale. Research in Nursing and Health, 10(6), 357-365.

Seefeldt, V., Malina, R. M., \& Clark, M. A. (2002). Factors affecting levels of physical activity in adults. Sports Medicine, 32(3), 143-168. https:// doi.org/10.2165/00007256-200232030-00001

Tatar, Y. (2010). Body image and its relationship with exercise and sports in Turkish lower-limb amputees who use prosthesis. Science \& Sports, 25(6), 312-317. https://doi.org/10.1016/j.scispo.2010.02.001

Thomas, D. R. (2006). A general inductive approach for analyzing qualitative evaluation data. American Journal of Evaluation, 27(2), 237-246. https://doi.org/10.1177/1098214005283748

Vissers, M., van den Berg-Emons, R., Sluis, T., Bergen, M., Stam, H., \& Bussmann, H. (2008). Barriers to and facilitators of everyday physical activity in persons with a spinal cord injury after discharge from the rehabilitation centre. Journal of Rehabilitation Medicine, 40(6), 461467. https://doi.org/10.2340/16501977-0191

Waters, R. L., \& Mulroy, S. (1999). The energy expenditure of normal and pathologic gait. Gait \& Posture, 9(3), 207-231. https://doi. org/10.1016/S0966-6362(99)00009-0

Wetterhahn, K. A., Hanson, C., \& Levy, C. E. (2002). Effect of participation in physical activity on body image of amputees. American Journal of Physical Medicine \& Rehabilitation, 81(3), 194201. https://doi.org/10.1097/00002060-200203000-00007

World Health Organisation. (2010). Global Recommendations on Physical Activity for Health. Retrieved from https://www.who.int/ dietphysicalactivity/global-PA-recs-2010.pdf

Woodard, C. M., \& Berry, M. J. (2001). Enhancing adherence to prescribed exercise: Structured behavioral interventions in clinical exercise programs. Journal of Cardiopulmonary Rehabilitation and Prevention, 21(4), 201-209. 


\section{Appendix 1}

\section{SEMII-STRUCTURED INTERVIEW GUIDE}

\section{Major questions}

1. How would you describe your own health at the moment?

2. Tell us about how you manage your own health at the moment?

3. What kind of things affect your ability to manage your own health and activity level?

a) How confident do you feel in your abilities to manage your activity levels by yourself?

4. What does physical activity mean to you?

a) Why is it important?

b) How do you think your physical activity at the moment impacts on your ability to perform everyday tasks?

5. Tell us about your physical activity?

a) What benefits have you received from being physically active? (such as mental, physical, social)

6. What things encourage you to be active?

a) What things prevent you from being active right now (such as societal, personal)?

b) How do facilities enable or prevent you from being active (such as taxis, foot paths, transport, infrastructure, finances)?

7. What type of support do you receive to aid you in being active (such as family or community or government agencies?)

8. How confident do you feel doing physical activity?

\section{Probing questions}

1. You mentioned ... how did you feel about that? Could you tell me a little more?

2. How do you deal with that? What kind of things do you do to get around that?

3. Why is that important to you?

4. Please explain further.

5. Can you give us an example of that? When did you experience this? 


\section{Appendix 2}

\section{SUPPORTING QUOTES FOR MAJOR THEMES}

\section{Attitude}

P6D

- That's [physical activity] my freedom you know, it still means that I've got my, my freedom...

- And you know when I'm out there on the water, just to be out of the house. You know it gives you ... in my mind I'm like, look aye I'm still able to do these things

- Like I said, doing my gardening outside, I can do that because I am doing it.

- I don't want anybody to do that for me.

- I am passionate about fishing, I'm passionate about gardening and I can still do those things.

P3T

- I don't feel I need any support.

- You're certainly not going to let anyone judge you as, you know, as disabled or crippled.

- $\quad$ There is nothing that I want to do that I'm prevented from doing.

- I can go out and spend all day in the garden, I can go shopping with my wife, I can do things you know that still makes me feel good.

P4T

- I'm not young but I don't want to walk around with a stick. I'd rather walk myself.

- The last four or five years I have been fine on my own... I haven't needed any help.

- It's good to find an exercise you enjoy.

P2T

- Well you try and do everything yourself... You're very independent.

P7D

- I work on the attitude that I can do anything at all that hasn't been proved to me that I can't do it. Some things take a lot longer than they used too, but I persevere.

- Well, I'd like to be able to live a normal life! But I can't anymore.

- No, I have to have the wife to help me.

P5T

- I used to have home help and I used to have people do my shopping for me, but I can manage that on my own now.

- Like I say, I live alone and no one else is gonna do anything else for me. Gotta do it myself.
Health

P4T

- ... You get enough problems with life, aches and pains, without adding unfit ...

- But glad I did [keep active] cos you know you can't stop the rest of your life because you have an accident... It's a bit of a hindrance but hey, got to get on with life don't ya.

- I think exercises is important, you know, especially when you get to my age.

- I think it's important to keep as fit as you can.

- I'm pretty chuffed about that. Yeah so. Umm I'm in excellent health.

- ... It's hard to exercise with a disability.

- My stump stops me.

- It's bad enough trying to find a job at that age without a disability, but with a disability, it's hugely against ya.

P6D

- I've got to keep my mind you know, alive and active instead of dwelling on the meanest things in life you know, the things that I can't do.

- I mean it helps you keep a positive attitude to life.

- $\quad$... because my picture of diabetic is an obese person, a sickly person, who's not active and doesn't work and all of that.

- You know l'm still, I'm still doing a lot of physical things.

- I need those exercises to be where I am today.

P3T

- Benefits [of physical activity]? Look I feel better about myself, I don't, um, dwell on having lost a leg.

- Can only walk maybe $50 \mathrm{~m}$ at a quick rate before I've got to stop and relax my stump inside the leg.

P2T

- Try and walk around as much as I can.

- I think you've got to keep fit... you've got to keep mobile.

- You know I trip over a fair bit now, just you know you catch your foot on something and go ... ass over kite.

- I can't walk a long way or for a long time, only about half a $\mathrm{K}$ [kilometre] would sort of pull me up, I'd have to stop.

P7D

- I can hardly walk, I fall over a lot... If it involves standing up, I fall over.

- I've got virtually no balance at all.

- My complete lack of any balance. My lack of any strength. 
P5T

- Like I say, I can only get out once a week, so I don't really know, I guess I feel a bit better once I'm out.

- I do the vacuuming, mop the floor. Getting around the house is fine, it's just going out anywhere is hard.

Social support

P4T

- I have a lot of friends who are interested in the same sort of things which is good.

- We talk about things and upcoming events and that, so yeah, I enjoy that very much.

- I sort of don't have anybody with a boat to go out with (insufficient social support).

- Not so much now but I did when I first had my accident, yeah, they all came round.

- Just being there.

- You know it's nice to have your family around and that.

P6D

- As long as I'm not by myself, you know as long as I'm with family members.

- I need somebody around me to dig the garden up and so forth.

- But I think my own church group, you know because my church, they have activities which, you know, you can go there and have a chat.

- I can't do that so they have to do that, they do that for me.

- I can still get out there and fish because I got friends that take me out fishing.

- $\quad$ in the morning I can't dress myself properly (insufficient social support).

P7D

- We go out together, take a picnic lunch and go out to spots that lookout over the beach and that sort of thing.

- $\quad$ But I did get very lonely - and we've got a fairly good marriage I think.

- Both my wife and I have mobility scooters.

- Well it keeps the mind active for one uhh and I'm a fairly sociable person and I do enjoy the interaction with other people.

- No, I have to have the wife to help me.

P2T

- Oh, heavy lifting and stuff like that I have to get my son around to help me.

- Nobody caters for the disabled (insufficient social support).
- Once you get out of hospital you never see anybody (insufficient social support).

- You're sort of left to your own devices (insufficient social support).

- Well if you look around there's not a lot of help round (insufficient social support).

P3T

- My wife will take my arm, just for balance, just in case someone bumps into me.

P5T

- Like I say, I live alone and no one else is gonna do anything else for me. Gotta do it myself.

- I was pretty scared because I'm on my own I haven't really got any family or anything like that I just live alone.

- Like I said, I'm housebound all the time.

- I've got no way of getting around you see.

- Well I guess lack of transport, I just can't really get around.

Environment and services

P4T

- Yeah when the weathers nice, it's nice to get up early, the early sunrise.

- I got a left-hand accelerator fitted onto the car because I can't use the right one.

- I use a disability sticker on the car so I park as close as I can to the um when I go shopping.

- I don't feel quite so umm what's the word? ... Confident, on wet, wet tiles or um, footpaths.

- Definitely got to be careful of footpaths, especially if it's raining, it's slippery

- They're pretty well situated [disability parks], there's quite enough of them

- So, you've got to pay to be in the park, that's what annoys you when you get people park in them.

- Used to have a caregiver but she's passed away.

- They made sure the house was wheelchair compatible, did the bathroom and put a lift, out the back so I could umm, get the wheelchair in the house,

P6D

- When I'm out there on the water, just to be out of the house.

- I've got an elevator outside my house to be able to get in and out of the house.

- The shower is changed; you know I don't have a bathtub where I can wheel the wheelchair inside the shower.

- We don't go anywhere that doesn't handle disabled people. 
- I'm finding the steps to become a bit of a hazard (insufficient support).

- I like a handrail when I'm going up and down steps.

- But if I asked them to put a ramp in, they would. She's told me that.

- I have to use a shower stool all the time. I find it a bit safer, you don't slip over.

- I put handrails in my shower. Things like that.

- But I would like to see more disabled facilities in the likes of motels and resorts and things like that (insufficient support).

- When they build houses, it should be compulsory to put a handrail in the shower. And anti-slip floors (insufficient support).

- You know for trimming branches and that but you don't get any assistance with that (insufficient support).

P5T

- Uhh physiotherapists, they got me a cane but it's not very good so I still use the crutch.

- I can do the shopping then catch a taxi home.

- Lack of transport I just can't really get around (insufficient support).

- It's so hard for me to actually do anything, because I have to walk. I've got no way of getting around you see (insufficient support).

- I tried to get a car, but my finances [inaudible] and couldn't get support to get a car. If I have to get anywhere, my neighbours will give me a lift (insufficient support).
Both my wife and I have mobility scooters and I get around a lot and travel around a lot on this.

- I've got a big one [mobility scooter] and I'm a fairly big guy myself and I do a lot of miles.

- We were going down there and they really put it out for us, they went and took us around and didn't cost us anything.

- You can get - well tourists can - get mobility scooters for free supplied by the council.

- I find that uhh I am restricted by the council gates and fences and such, where they put things in front of anybody on a scooter (insufficient support).

- Because there's no cover on the scooter and if it's raining, I get drenched (insufficient support).

- [The Lions Club] they went and took us around and didn't cost us anything.

P3T

- $\quad$ Limb service supplied me with legs whenever I've needed it. 